\title{
Intonational marking of given and new information: Some consequences for comprehension
}

\author{
J. KATHRYN BOCK and JOANNE R. MAZZELLA \\ Michigan State University, East Lansing, Michigan 48824
}

\begin{abstract}
The role of intonation in conveying discourse relationships in auditory sentence compre hension was investigated in two experiments. Using the simple comprehension time paradigm, Experiment 1 found that sentences with accented new information were understood faster than sentences with a neutral intonation contour and that the presence of accent in context sentences facilitated comprehension of subsequent targets. Both experiments showed faster comprehension times in conditions in which accent placement was appropriate for the information structure of the sentence. In Experiment 1, comprehension times were faster when the accent fell on the information focus than when it fell elsewhere in the sentence. In Experiment 2, faster times resulted when new information was accented and given information was not, compared to conditions in which this accent pattern was reversed. This effect held for both active and passive sentences, and whether the new information occurred in the subject or object position.
\end{abstract}

In contrast with the semantic, syntactic, and lexical aspects of language, effects of the prosodic features of utterances on comprehension have received relatively little attention. An utterance's intonation can, however, have a profound impact on its interpretation: Given the proper stress pattern, a sentence such as "That was a thrilling experience" can mean that the experience was quite the opposite of thrilling (Cutler, 1976). Intonation also carries a heavy burden in conveying the information structure of an utterance, marking different components as given or new (Chafe, 1974; Cutler, 1976; Cutler \& Isard, 1980). Appropriate intonation may therefore facilitate the hearer's understanding of the relationship between a particular sentence and its discourse context. This paper examines certain effects on comprehension of variations in the stress patterns accompanying alternative arrangements of given and new information within sentences.

The intonation of sentences reflects a variety of influences (Cutler \& Isard, 1980). Some of these are within-sentence factors, including the syntax and the distribution of stressed syllables across the words of the

This research was partially supported by funds from the College Scholar Program of the College of Social Science at Michigan State University. Experiment 1 formed a portion of a thesis submitted by the second author to Michigan State University in partial fulfillment of requirements for the MA in psychology. We thank Gordon Wood and Rose Zacks for extensive advice on the experiments, David Irwin and David Ehresman for assistance in programming, data analysis, and preparation of stimulus materials, and Leonard Silverman for running subjects in Experiment 2. Requests for reprints should be sent to Kathryn Bock, Department of Psychology, University of Pennsylvania, 3815 Walnut Street, Philadelphia, Pennsylvania 19104. sentence. The prosodic structure that results appears to make important contributions to the comprehensibility of individual sentences (Dooling, 1974; Geers, 1978; O'Connell, Turner, \& Onuska, 1968; Shields, McHugh, \& Martin, 1974; Weener, 1971; Wingfield \& Klein, 1971).

Intonation is also substantially affected by a variety of intersentential or discourse relationships (Chafe, 1976; Gunter, 1966). In particular, the placement of the primary emphasis or the accent (Bolinger, 1961) within a sentence often seems to be determined by the location of the new information that the sentence contains: Information that is novel in the context of prior discourse is accented, whereas old, given, or background information is not. Although there are other ways in which given and new information can be marked, intonation may be the principal means for indicating the distinction in English. Compared to certain other languages, English relies more on stress patterns and less on devices such as word order for information structure cues (MacWhinney \& Bates, 1978).

Some evidence for the importance of intonation in conveying information structure comes from the observation that children acquiring English appear to employ intonation appropriately very early to mark new or salient information. Wieman (1976), in a sample of five children between the ages of 21 and 29 months, found that when their two-word utterances departed from certain canonical stress patterns, the deviations were attributable to the accenting of the word in the utterance that carried new information. In more controlled tasks, children as young as 3 years display adult levels of competence in using stress to mark new information (Hornby \& Hass, 1970; MacWhinney \& Bates, 1978). Stress also seems to be children's preferred way of marking infor- 
mation structure (Hornby, 1971; MacWhinney \& Bates, 1978), although Hornby (1971) observed a decline in its use with age for the first- through fifth-grade children in his study.

In adult language use, there are a few observations relevant to assessing the role of this system in discourse comprehension. Hornby (1972) presented subjects with a spoken sentence that inaccurately described two pictures and required the subjects to choose which of the pictures the sentence was intended to describe. For example, the sentence "The INDIAN is building the igloo" was accompanied by a picture of an Eskimo building an igloo and one of an Indian building a tepee. Subjects tended to select the picture in which the accented word (INDIAN in the example) mismatched the picture, suggesting that the subjects viewed speakers as more likely to correctly designate given or presupposed information than new or asserted information. A later experiment (Homby, 1974) showed that listeners perform as though this were true in the immediate verification of sentences as well. Subjects heard cleft and pseudocleft sentences (e.g., "It's the boy that the girl is kicking"; "The one the girl is kicking is the boy"), followed by a $50 \mathrm{msec}$ exposure to a picture that mismatched either the agent or the object of the action of the sentence. Subjects made significantly fewer errors when the picture mismatched the clefted or pseudoclefted element. Since such sentences are naturally spoken with the accent within the clefted ("It's the BOY that the girl is kicking") or pseudoclefted ("The one the girl is kicking is the BOY") noun phrase (see the findings of Allen and O'Shaughnessy cited by Cutler, 1976), this effect may be partially attributable to a tendency to attend to and verify the emphasized constituent first. Although similar effects are obtained with visual presentation of sentences (Carpenter \& Just, 1977a; Langford \& Holmes, 1979), implying that this may not be the entire explanation, such an interpretation is supported by the results of other experiments that explicitly varied accent in a sentence-picture verification task (Hornsby, Carr, \& Bock, Note 1).

The effects of given and new information on understanding language have been examined most frequently in investigations of sentence comprehension in discourse contexts. Many of these studies were motivated by Clark and Haviland's (1977) sketch of the procedures required to interpret contextualized sentences, in which the given-new distinction plays a central role. These procedures, collectively called the given-new strategy, specify three steps that must be carried out for a sentence to be understood: (1) The given and new information must be identified, (2) any given information must be related to its antecedent, and (3) the new information must be incorporated into memory. Problems in performing any of these operations should disrupt comprehension.

The second step of the given-new strategy has been the most thoroughly examined of the three, with a number of experiments showing that a sentence is more readily understood when the immediately preceding text provides appropriate antecedents for its given information (Clark \& Sengul, 1979; Garrod \& Sanford, 1977; Haviland \& Clark, 1974; Yekovich \& Walker, 1978; Yekovich, Walker, \& Blackman, 1979). However, some support for the first step, identifying the given and new information in the sentence, comes from experiments that have shown facilitation of comprehension by clear, accurate marking of what is given and new. Thus, clefted and pseudoclefted noun phrases are clearly marked as new information; if this marking is appropriate, comprehension is easier than if it is not (Carpenter \& Just, 1977b). Likewise, givenness tends to be associated with the surface subject position of sentences, whereas new information more often occurs in object position (Halliday, 1967), and this arrangement also appears to be more comprehensible than the opposite ordering (Yekovich et al., 1979).

Although such syntactic devices as clefting, pseudoclefting, and given-new ordering seem to be effective indicators of given and new information, the developmental evidence reviewed earlier suggests that they may be subsidiary to intonational marking, particularly in spoken English. Since the sentences in the experiments on comprehension in discourse contexts were presented visually and read silently by the subjects, the effectiveness of intonation as a marker for information structure and its influence on comprehension are unclear. If intonation is a fundamental system for conveying information structure in English, it should be possible to facilitate auditory sentence comprehension simply by accenting new information or to disrupt it by accenting given information. The two experiments reported below examined several variations of this hypothesis, using the simple comprehension time paradigm employed in previous reading comprehension experiments. The participants listened to pairs of sentences in which the initial sentence (the context sentence) established some minimal background information, and the second sentence, the target, was related to the context in some way. Participants indicated when they felt they had understood each sentence by pressing a key (Clark \& Sengul, 1979; Haviland \& Clark, 1974; Yekovich \& Walker, 1978; Yekovich et al., 1979).

Both experiments explored the basic question of facilitation vs. disruption of comprehension by appropriate vs. inappropriate use of intonation to mark information structure. In addition, Experiment 1 examined the effect of presence vs. absence of accent in the context sentence on comprehension of the target, and the effect of omitting accent in the target sentence. Experiment 2 varied the voice of the target sentence (active vs. passive) and the position of the accent in the target sentence (surface subject vs. surface object).

\section{EXPERIMENT 1}

What is given or new in a sentence depends on the relationship of the information in the sentence to material in prior utterances or text. These relationships 
may be established by the presuppositions of the previous discourse. A particularly effective way to create these presuppositions is with a prior "wh-" question (Chomsky, 1971 ; van Dijk, 1977). For example, the new information in a simple sentence such as "Mary went to the store" is different when preceded by the question "Where did Mary go?" than when preceded by "Who went to the store?" In production tasks, the differences in information structure created by these kinds of variations in prior questions result in different syntactic arrangements of the components of the same basic proposition (Bock, 1977; Bock \& Irwin, 1980). Cutler and Fodor (1979) found that comprehension was affected when prior questions were used to manipulate sentence focus (the location of the asserted or most informative material). They preceded a sentence such as "The man on the corner was wearing the blue hat" either with the question "Which man was wearing the hat?", so that the word "corner" was the focus, or with the question "Which hat was the man wearing?", so that the word "blue" was the focus. Cutler and Fodor examined phoneme-monitoring reaction times to initial phonemes of such words both when they were and when they were not focused, using the same recording of each sentence in all conditions. They found faster reaction times when the word bearing the target phoneme was focused than when it was not.

Experiment 1 employed a related method of establishing discourse presuppositions, one that relied on varying the intonation pattern of a context sentence. Thus, the question "Who fixed the radio?" and a sentence such as "ARNOLD didn't fix the radio" both establish the presupposition that someone fixed the radio. This presupposition can be changed by varying the location of the accent, as well as by omitting it: "Arnold didn't FIX the radio" presupposes that Amold did something else to the radio, whereas a relatively neutral rendition of the sentence conveys neither of these presuppositions, although it is compatible with both states of affairs. The accent delineates what the focal information in subsequent discourse should be, the actual radio repairer, or what Arnold really did to the radio.

Variations in intonation like these were used in the context sentences in Experiment 1, coupled with target sentences whose stress patterns marked focal information appropriately or inappropriately. Thus, in "DORIS fixed the radio," the accent falls appropriately on focal information when the sentence is preceded by "ARNOLD didn't fix the radio," but when preceded by "Arnold didn't FIX the radio," the accent falls inappropriately on nonfocal information. If intonation effectively indicates the information focus in sentences, appropriate accent should produce faster comprehension times than inappropriate accent. When the stress pattern of the context sentence is neutral, with no clear accent, comprehension times for the targets should be intermediate, since in these cases additional processing may be required to identify the discourse presuppositions or antecedents, although the accent in the target is appropriate.

Since it would be possible for inappropriate accent to disrupt comprehension without appropriate accent necessarily facilitating it, Experiment 1 also included a control condition in which the intonation patterns of both the context and the target sentences were neutral. If information structure is important in comprehension, and intonation is an effective marker for it, this condition should result in slower comprehension times than the condition in which the neutral context sentence is followed by an accented target.

\section{Method}

Participants. The participants were 40 native speakers of English who served in the experiment for extra credit in an introductory psychology course at Michigan State University.

Materials. The auditory stimulus materials were constructed from 20 sets of four sentence pairs each, examples of which are presented in Table 1. All 20 sets are listed in Appendix A. The four pairs in each set were identical except for differences in the location of the accent or primary stress within the two sentences. Each pair of sentences consisted of a context sentence and a related target sentence. The context sentence in all pairs was a simple negative declarative sentence. The structure of the target sentence was parallel to that of the context, except that it was positive and replaced a content word from the context sentence with a different word.

Four types of accent relations were represented by the sentence pairs in each set. In the first type (appropriate target accent; see Table 1), the content word in the context sentence that was most prominently stressed corresponded to the changed and accented word in the target. In the second type (inappropriate target accent), the same target sentence was preceded by a context sentence in which a different word was accented, thereby creating a presupposition for which the target stress pattern was inappropriate. In the third type (no context accent), none of the words in the context sentence received special emphasis. These three pairs employed identical target sentences. The fourth type, a control pair, omitted accent in both the context and the target.

The word accented in the target sentence was either the subject, verb, object, adjective, or object of the preposition of the sentence. Equal numbers of sentence sets instantiated each of these stress assignments.

Table 1

A Sentence Set from Experiment 1

\begin{tabular}{lll}
\hline \multicolumn{1}{c}{ Condition } & \multicolumn{1}{c}{ Context Sentences } & Target Sentences \\
\hline Appropriate target accent & ARNOLD didn't fix the radio. & DORIS fixed the radio. \\
Inappropriate target accent & Arnold didn't FIX the radio. & DORIS fixed the radio. \\
No context accent & Arnold didn't fix the radio. & DORIS fixed the radio. \\
Control & Arnold didn't fix the radio. & Doris fixed the radio. \\
\hline
\end{tabular}


Four presentation lists of 20 sentence pairs each were constructed. Every list contained five sentence pairs representing each of the four possible conditions, with no list containing more than one sentence pair from any sentence set. Across all lists, each of the 80 possible sentence pairs was used only once. The same random order of experimental conditions was used for all presentation lists, with sentences having similar stress assignments (subject, verb, etc.), but from different sets, appearing in the same positions across lists. Three additional sentence pairs, similar in form to the experimental pairs, were added to the beginning of each list to serve as practice items. The same prac tice pairs were used for all presentation lists.

Each unique sentence in the complete stimulus set was recorded once by a female speaker on audiotape using a Revox A-700 tape recorder and an AKG D120E microphone. Within each set of sentence pairs, the unique sentences consisted of three versions of the context sentence (each with a different stress pattern) and two versions of the target sentence (one with and one without accent). The stress patterns of the recorded sentences were checked by a second person to insure that the location of the accent was correct in the accented sentences and that no words were prominently stressed in the neutral, unaccented sentences. All sentences whose intonation did not clearly conform to the intended patterns were rerecorded

These recordings were used to construct the four different context/target combinations. The recorded sentences were digitized and stored on magnetic disc using a PDP 11/40 computer interfaced with analog-to-digital and digital-to-analog converters (Model DAC-16, 3 Rivers Computer Corporation). The analog-to-digital converter sampled the auditory input at a rate of 10,000 times/sec; at this rate, the analog conversions of the digitized stimuli were indistinguishable, under normal listening conditions, from the original recordings. The beginnings and endings of the digitized records of the sentences were edited by visual inspection of a graphic display of components of the auditory waveform for each sentence, accompanied by auditory playback of the analog conversion of the sentence, to ensure relatively uniform onset and offset of all sentences.

The four presentation lists were constructed by playing sentences back in the order predetermined for each list and recording them on one channel of an audiotape. Recording was controlled by a program that placed a timing tone at the edited beginning and end of each sentence on another tape channel. The program inserted a 5 -sec silent interval between sentence pairs and a $1-\mathrm{sec}$ interval between the two sentences in each pair. The purpose of this spacing was to emphasize the relationship between the paired sentences.

For each presentation list, a yes-no recognition test was constructed that included all of the experimental target sentences from the list plus an equal number of distractor sentences similar in structure to the targets, but employing different words. The 40 sentences for each test were typed in random order on a single page, with each sentence followed by a blank for the participant to indicate his or her response.

Procedure. Participants were tested individually. They were seated in front of a response panel and listened to the binaurally presented stimuli through headphones (Koss Pro/4AA). They were instructed to listen carefully to each sentence and to press the rightmost lever on the panel as soon as they understood what the sentence meant. They were not explicitly told that the sentences were related to each other or that they occurred in pairs. All 23 sentence pairs ( 3 practice plus 20 experimental pairs) in a single presentation list were presented without a break.

Stimulus presentation and response monitoring and timing were controlled by a PDP $8 / \mathrm{i}$ computer interfaced with a TEAC A3340S tape recorder. Since it was possible for participants to respond before the end of a sentence, comprehension times were measured from both onset and offset of the sentences. If no response had occurred by the time a sentence ended, the tape stopped and did not restart until the participant responded. When a response was made before a sentence was completed, however, the tape continued.

The recognition memory test was administered after the presentation list was completed. Participants were asked to indicate whether each sentence was one that had just been heard by writing "yes" or "no" after each sentence on the test. Participants were not informed of the memory test at the beginning of the experiment.

All of the participants in Experiment 1 performed a related experimental task during the same session. Half completed the related task before Experiment 1, and half following Experiment 1.

Design. The four experimental conditions represent four levels of the accent factor (appropriate target accent, inappropriate target accent, no context accent, and control). Each of the 40 participants heard a different set of five items (sentence pairs) in each of these four conditions. Different participants heard the four different versions of each item corresponding to the four experimental conditions.

\section{Results}

The comprehension times used in the analyses were measured relative to the ends of the sentences in order that the times would not reflect the durations of the sentences. Times for responses that occurred prior to the ends of sentences were treated as negative; a response that occurred $15 \mathrm{msec}$ before the end of a sentence thus yielded, for purposes of the analyses, a comprehension time of -15 msec.

The mean comprehension times for target sentences in the four conditions of the experiment are shown in Table 2. The mean target comprehension times for each participant and item in each condition were submitted to analyses of variance that treated both participants and items as random factors (Clark, 1973; Coleman, 1979). The alpha level for significant effects, unless otherwise indicated, was set at .05 .

The overall analysis showed that the four conditions differed significantly: with participants random $[F(3,114)=9.02]$, with items random $[F(3,57)=6.38]$, and with both random $\left[\min F^{\prime}(3,133)=3.74\right]$. Planned comparisons revealed significant differences between the appropriate target accent condition and each of the other three conditions (the halfwidths of the $95 \%$ confidence intervals were $54 \mathrm{msec}$ in the analysis with participants random, and $67 \mathrm{msec}$ in the analysis with items random). The no context accent condition differed significantly from the control condition in both analyses. The 50-msec difference between the inappropriate target accent condition and the no context accent condition did not quite reach significance in either analysis,

Table 2

Experiment 1: Mean Target Sentence Comprehension Times (in Milliseconds)

\begin{tabular}{lc}
\multicolumn{1}{c}{ Condition } & $\begin{array}{c}\text { Compre- } \\
\text { hension Time }\end{array}$ \\
\hline Appropriate Target Accent & $-14^{*}$ \\
No Context Accent & 75 \\
Inappropriate Target Accent & 125 \\
Control & 143 \\
\hline
\end{tabular}

*Equiralent to $14 \mathrm{msec}$ before the end of the target sentence. 
although it was marginal $(\mathrm{p}<.10)$ in the participants' analysis. The $18-\mathrm{msec}$ difference between the control and inappropriate target accent conditions was not significant.

Because heightened stress is correlated with increased duration (Lehiste, 1970), the lengths of the accented and unaccented sentences were measured and compared. The mean duration of accented sentences $(2,125 \mathrm{msec})$ was significantly greater than that of unaccented sentences $(1,861 \mathrm{msec})[F(1,99)=12.8]$. The comprehension times for accented vs. unaccented context sentences were analyzed to investigate possible effects of this difference on comprehension. However, the comprehension times for accented context sentences, with a mean of $261 \mathrm{msec}$, did not differ significantly from those for unaccented context sentences, with a mean of $281 \mathrm{msec}($ all $\mathrm{Fs}<1$ ).

The order in which participants served in Experiment 1 , relative to the related experiment, was included as a factor in the overall analysis. There was a trend toward faster comprehension times when Experiment 1 was second, but the interaction between the order factor and the accent factor was not significant in any of the analyses.

Recognition test performance was $90 \%$ correct overall, indicating that participants were attending to the sentences while performing the task.

\section{Discussion}

These results demonstrate that intonation, as a device for conveying the information structure of sentences, makes a substantial contribution to their comprehension. The comprehension times for target sentences were significantly shorter when new, focal information was accented (appropriate target accent) than when nonfocal information was accented (inappropriate target accent), suggesting that appropriate intonational marking of new information facilitated comprehension. This conclusion is strengthened by the contrast between the no context accent condition and the control condition. The only difference between these two conditions was in the presence of accent within the target sentence; comprehension times were significantly shorter when the target was accented. These findings complement and extend earlier observations (Carpenter \& Just, 1977b; Yekovich et al., 1979) that the syntactic marking of given and new information influences the comprehension of written sentences. In the current experiment, only intonation served to distinguish new information. Nonetheless, in line with claims for the role of intonation in marking information structure (Chafe, 1974; Gunter, 1966), its appropriate use speeded the comprehension of simple active sentences.

The significant difference between the appropriate target accent condition and the no context accent condition shows that the specification of a discourse presupposition by the context sentence's accent pattern also contributed to comprehension of the target sen- tence. This finding is in line with the results of Yekovich et al. (1979), who found that the placement of information in context sentences influenced target comprehension: Target comprehension times were faster when presupposed information occurred in subject position and when focal information occurred in object position within context sentences than when this order was reversed. Since there is a general relationship between presupposed vs. focal information and subject vs. object position, this placement appears to have aided identification of the context's information structure, which in turn supported target comprehension. In the present experiment, a context sentence such as "SYLVIA didn't pet the monkey" specified two pieces of information necessary for the understanding of the subsequent contrastive sentence (Chafe, 1976): A particular unfilled role (the one who petted the monkey) and certain background information (that the monkey had in fact been petted). In comparison, the unaccented context sentence "Sylvia didn't pet the monkey" is ambiguous with respect to which role is unfilled and what information is presupposed. In terms of the given-new strategy (Clark \& Haviland, 1977), the accented version of the sentence may have promoted comprehension of a following target sentence, for example, "DAVE petted the monkey," in either of two ways: Its presupposition provided a clear antecedent for the given information in the target sentence, and its specification of an unfilled role supplied an explicit memory address for the new information.

The regular difference in duration between accented and unaccented sentences dictates that any conclusions based on this contrast be treated cautiously. So, although comprehension times for targets were shorter when targets were accented than when they were not, and when contexts were appropriately accented than when they were unaccented, the presence of accent is naturally confounded with greater length. As a result, the faster responses for accented targets may be due in part to the availability of more time for processing. Although the absence of a significant effect of accent on the comprehension times for context sentences makes a simple processing time explanation somewhat less probable, the 20 -msec difference between the two was nevertheless in the direction predicted by such a hypothesis.

\section{EXPERIMENT 2}

In addition to intonation, there are various syntactic and lexical devices that are used to distinguish given from new information. One frequently discussed syntactic marker is placement of given information in the surface subject and new information in the predicate of the sentence (Chafe, 1970; Firbas, 1966; Halliday, 1967). In visual sentence processing, Yekovich et al. (1979) have shown that such an arrangement results in faster comprehension times than the opposite ordering.

Very little is known about the relationship between 
such syntactic devices and intonation. There do seem to be gross associations between syntactic and intonational indicators of information structure: The accent in cleft and pseudocleft sentences naturally falls on the clefted and pseudoclefted noun phrases (Allen \& O'Shaughnessy, cited by Cutler, 1976), which have been taken to represent the information focus (Hornby, 1974), and primary stress in the so-called neutral intonation contour falls at the end of the sentence (Cutler \& Isard, 1980), the canonical position for the information focus. Such correlations may be attributable to the influence of intonational preferences on syntax, with syntax being adjusted to conform to prosodic patterns. Alternatively, intonation and syntax may constitute independent, complementary systems for marking information structure.

Experiment 2 was designed to explore the contributions of intonational and syntactic markers of information structure to sentence comprehension. Using the simple comprehension time paradigm, accent and subject vs. object placement of given and new information were varied factorially in target sentences, with the stress pattern of the context sentences controlled. The complementary systems hypothesis suggests that accent and location of given and new information should make independent contributions to comprehension time, whereas the intonational primacy hypothesis, in its strongest form, predicts that intonation alone should affect comprehension.

Both active and passive target sentences were used in Experiment 2. Since passive sentences seem to mark information structure more strongly than simple actives (Anisfeld \& Klenbort, 1973; Hornby, 1974), the appropriate positioning of given and new information may make a greater contribution to the comprehension of passives than actives. However, if the effects of subject vs. object placement are general, they should not differ across the two sentence types.

\footnotetext{
Method

Participants. Forty eight undergraduates at Michigan State University served in the experiment as an extra-credit option in an introductory psychology course. All were native English speakers, and none had participated in the previous experiment.

Materials. The auditory stimulus materials were constructed from 24 sets of eight pairs of context and target sentences. One of these sets is presented in Table 3, and all of the sets are listed in Appendix B. Each set was composed of all possible pairs of two different context sentences preceding four different target sentences. The context sentences were simple actives that were the same except for their surface subject and surface object
}

noun phrases. Insofar as possible, no obvious stress was placed on any part of the context sentences, although they were spoken as naturally as possible within this constraint. The four target sentences consisted of two versions of both the active and passive variants of a single simple sentence. Once version accented the surface subject, and the other version accented the surface object. The surface subject of one of the context sentences matched the surface subject of the active target and the surface object of the passive target. The surface object of a second context sentence matched the surface object of the active target and the surface subject of the passive target.

The eight experimental conditions that resulted from pairing the two context sentences with the four versions of the target were defined by (1) whether the target was active or passive, (2) whether the surface subject or surface object constituent in the target was accented, and (3) whether the subject and object constituents of the target positioned the given and new information appropriately, given the accent pattern (e.g., when the subject was accented, new information was located in the subject), or positioned it inappropriately, given the accent pattern (e.g., when the subject was accented, new information was located in the object).

Two different presuppositional relationships, each used in 12 sentence sets, were employed in writing the sentence pairs. Each relationship was distinctively marked in the target sentence by an adverb, "too" or "either" (see Haviland \& Clark, 1974, Experiment 3, for a discussion of the presuppositions associated with these adverbs). All of the sentences in "too" pairs were positive, and all those in "either" pairs were negative.

In addition to the two context sentences used in the experimental sentence pairs, an unrelated context sentence was paired with each of the four target sentences in each sentence set. For example, the context sentence "Lila kissed Michael" was paired with each of the target sentences in the set in Table 3. The purpose of these unrelated context sentences was to discourage participants from attempting to predict the object of the verb in the target sentences. In the experimental sentence pairs, whenever the subject of the target sentence differed from both the subject and object of the context sentence, an active target sentence's object matched the object of the context sentence, and the object in a passive target sentence matched the context sentence's subject. A pilot experiment suggested the possibility that this predictability would influence participants' responses.

Four presentation lists were constructed, each composed of three blocks of 24 items, for a total of 72 items in every list. Each list contained 48 experimental sentence pairs, 6 from each of the eight experimental conditions, and 24 sentence pairs in which the context and target were unrelated. Within lists, three sentence pairs from each sentence set were employed, representing the possible combinations of one version of the target sentence with three different context sentences (including the unrelated context). Each of these was assigned to a different block. Across lists, any given sentence pair was used only once. The same random order of items was used for all presentation lists, so that sentence pairs from the same set with the same context sentence appeared in similar positions in their respective lists. At least one and no more than four items in each condition appeared in each block. Four practice items similar in form to

Table 3

A Sentence Set from Experiment 2

\begin{tabular}{lll}
\hline \multicolumn{1}{c}{ Condition } & Context Sentences & \multicolumn{1}{c}{ Target Sentences } \\
\hline Active/Subject/Appropriate & Evelyn kissed Jeremy. & RHONDA kissed Jeremy, too. \\
Active/Subject/Inappropriate & Rhonda kissed Jason. & RHONDA kissed Jeremy, too. \\
Active/Object/Appropriate & Rhonda kissed Jason. & Rhonda kissed JEREMY, too. \\
Active/Object/Inappropriate & Evelyn kissed Jeremy. & Rhonda kissed JEREMY, too. \\
Passive/Subject/Appropriate & Rhonda kissed Jason. & JEREMY was kissed by Rhonda, too. \\
Passive/Subject/Inappropriate & Evelyn kissed Jeremy. & JEREMY was kissed by Rhonda, too. \\
Passive/Object/Appropriate & Evelyn kissed Jeremy. & Jeremy was kissed by RHONDA, too. \\
Passive/Object/Inappropriate & Rhonda kissed Jason. & Jeremy was kissed by RHONDA, too. \\
\hline
\end{tabular}


the experimental sentence pairs were placed at the beginning of the first block in each list. The same practice items were used for all four presentation lists.

The unique sentences in each set of sentence pairs (the three context sentences and the four target sentence versions) were prepared and assembled into lists using the procedures described in Experiment 1.

To check accent placement in the recorded sentences, four naive raters listened to the four tapes containing each presentation list and indicated on a written transcript where the heaviest stress fell in each context and target sentence. Each tape was evaluated by one rater. For the target sentences, each of which occurred three times within a given list, the percentages of agreement between the raters' accent assignments and the intended assignments were $100 \%, 100 \%, 98.6 \%$, and $93.1 \%$. Three of the five disagreements that produced the lowest percentage occurred for only one of the three occurrences of three different sentences, so that in each case the rater agreed with the intended assignments on two of the three occurrences. The remaining two disagreements occurred on the same sentence, although the rater agreed with the intended assignment on the third occurrence. For the context sentences, which were the same on all four tapes, there was a trend toward indicating the subject as the locus of heaviest stress, with the raters marking it on $62 \%$ of the sentences overall. The object, at $30 \%$, was next most frequent, and different components of the verb and auxiliary made up the remaining $8 \%$. There were large individual differences in these evaluations, however: For the four raters, the percentages of subject selection were $100 \%, 35 \%, 71 \%$, and $40 \%$. The stress patterns of the context sentences were thus relatively neutral in comparison to the targets.

For each presentation list, a yes-no recognition test was constructed that included a representative half of the target sentences and 12 distractor sentences, which used the verbs from those target sentences not included in the test, but with new subject and object noun phrases. The syntax of the distractors was similar to that of the targets. The 24 sentences for each test were typed in random order on a single page, with each sentence followed by a blank for the participant to indicate his or her response.

Procedure. The procedure followed was the same as that described for Experiment 1, except that participants were given a short break between blocks.

Design. Each of the 48 subjects contributed data to the eight cells of the factorial formed by crossing the two levels of the target sentence type factor (active vs. passive), the two levels of the stress factor (surface subject vs. surface object), and the two levels of the location factor (appropriate vs. inappropriate). Each subject received three versions of each item, each in a different experimental or unrelated context condition, and versions of six different items in every condition.

\section{Results}

The comprehension times used in the analyses, as in the previous experiment, were measured relative to the ends of the sentences. Mean comprehension times for the target sentences were computed for each participant and item in every condition. The 61 comprehension times exceeding $3,000 \mathrm{msec}$ were discarded $(10,13$, and 38 in the appropriate, inappropriate, and unrelated conditions, respectively, or $1.8 \%$ of all responses). The overall condition means, including the unrelated context conditions, are shown in Table 4.

The data were submitted to analyses of variance treating both participants and items as random effects; the level required for significance was set at .05 unless otherwise noted. These analyses excluded the data from the unrelated context conditions.
Table 4

Experiment 2: Mean Target Sentence Comprehension Times (in Milliseconds)

\begin{tabular}{ccccc}
\hline & & \multicolumn{3}{c}{ Placement* } \\
\cline { 3 - 5 } Voice & Accent & A & I & U \\
\hline Active & Subject & 207 & 221 & 406 \\
Active & Object & 187 & 232 & 356 \\
Passive & Subject & 239 & 326 & 402 \\
Passive & Object & 198 & 276 & 364 \\
\hline
\end{tabular}

Note $-A=$ appropriate,$I=$ inappropriate, $U=$ unrelated .

*Placement of accent relative to given and new information.

The analyses showed that the difference between the appropriate and inappropriate conditions, with faster comprehension times in the appropriate condition, was significant in all analyses $[F(1,47)=5.78$ for participants; $F(1,23)=26.63$ for items; $\left.\min F^{\prime}(1,64)=4.75\right]$. The interaction between accent placement and appropriateness, which tests the hypothesis that syntactic marking of information structure influences comprehension, was not significant in either analysis $[F(1,47)<1$ for participants and $F(1,23)<1$ for items]. The three-way interaction between voice, accent placement, and appropriateness was also not significant $[F(1,47)<1$ for participants and $F(1,23)<1$ for items], indicating that there was no reliable difference between passives and actives in the importance of the syntactic marking of information structure. Subject vs. object placement had no overall effect (all Fs $<1$ ).

The main effect of voice was significant in both the participants and the items analyses $[F(1,47)=5.96$ and $F(1,23)=5.35]$, reflecting generally faster comprehension times for active than for passive sentences. This effect was, however, marginal in the joint analysis $\left[\min F^{\prime}(1,59)=2.82, p<.10\right]$. The interaction between voice and appropriateness was significant in the analysis with items random $[F(1,23)=5.16]$, although not in the analysis with participants random $[\mathrm{F}(1,47)=2.64]$, or in the joint analysis $\left[\min F^{\prime}(1,70)=1.75\right]$. The interaction in the items analysis is attributable to the larger difference between passives and actives in the inappropriate than in the appropriate condition: The 75-msec difference between inappropriate passives and actives was well beyond the 34-msec halfwidth of the 95\% confidence interval for items, whereas the difference between appropriate passives and actives was a nonsignificant $21 \mathrm{msec}$.

Changes in performance over the three blocks of the experiment were evaluated in an analysis of variance that included block as a factor. The means are given in Table 5. The analysis was performed only with participants as a random effect, because each item did not occur in every condition in every block. There was a significant main effect of block $[F(2,94)=27.03]$ due to decreases in comprehension times in successive blocks: The mean comprehension times in Blocks 1, 2 , and 3 were 344,202 , and $134 \mathrm{msec}$, respectively. The main effects of appropriateness $[F(1,47)=8.81]$ and 
Table 5

Experiment 2: Mean Target Sentence Comprehension Times Over Blocks 1, 2, and 3 (in Milliseconds)

\begin{tabular}{ccccc}
\hline & & & \multicolumn{2}{c}{ Placement* } \\
\cline { 4 - 5 } Voice & $\begin{array}{c}\text { Accent } \\
\text { Placement }\end{array}$ & Block & A & I \\
\hline \multirow{3}{*}{ Active } & & 1 & 309 & 254 \\
& Subject & 2 & 158 & 239 \\
Active & & 3 & 172 & 114 \\
& & 1 & 293 & 375 \\
Oassive & & 2 & 212 & 161 \\
& & 3 & 130 & 159 \\
& & 1 & 368 & 424 \\
Passive & & 2 & 116 & 275 \\
& & 3 & 60 & 200 \\
& & 1 & 345 & 381 \\
& & 2 & 223 & 230 \\
& & 3 & 95 & 260 \\
\hline
\end{tabular}

Note- $A$ = appropriate, $I=$ inappropriate.

*Placement of accent relative to given and new information.

voice $[F(1,47)=7.01]$ were again significant. The interaction between appropriateness and voice was also significant $[F(1,47)=5.31]$, suggesting that variability attributable to the block factor was responsible for the failure of this interaction to reach significance in the primary analysis with participants random.

Two three-way interactions involving block were significant. First, the interaction between block, appropriateness, and accent location was significant $[F(2,94)=$ 4.46]: The appropriateness effect was reliable, with a $95 \%$ confidence interval halfwidth of $79 \mathrm{msec}$, for subjectaccented sentences only in the second block, and for object-accented sentences only in the third block. However, the direction of the effect was consistently in favor of faster comprehension times in the appropriate condition for both subject- and object-accented sentences in every block except the second, in which there was a 22 . msec reversal for object-accented sentences. Second, the interaction between block, accent location, and voice was significant $[F(2,94)=3.37]$; subject-accented actives were significantly faster than subject-accented passives in the first block, whereas object-accented actives were significantly faster than object-accented passives in the third block, with a $95 \%$ confidence interval half width of $66 \mathrm{msec}$. These interactions suggest some inconsistency in performance over blocks, which is most probably the result of the small number of trials in each condition within each block. No systematic trends across blocks, other than the overall decrease in comprehension times, were apparent.

Examination of the means in the unrelated condition revealed a general tendency for sentences with object accent to be responded to more rapidly than sentences with subject accent: The mean for subject-accented unrelated sentences was $404 \mathrm{msec}$, whereas for objectaccented unrelated sentences it was $360 \mathrm{msec}$. This 44-msec difference was tested and found to exceed the $95 \%$ confidence intervals for both participants (40 $\mathrm{msec})$ and items (35 msec). A similar effect appeared in the appropriate and inappropriate conditions in a trend toward faster comprehension times for objectaccented than for subject-accented passives, although the interaction between accent placement and voice was not significant $[F(1,47)=1.99$ for participants and $F(1,23)<1$ for items]. Object accent thus seems to have been associated with faster comprehension times in the more difficult conditions of the experiment.

The mean of the scores on the recognition test was $93 \%$ correct.

\section{Discussion}

These results show again that the appropriate use of intonation to mark given and new information facilitates the comprehension of sentences. The data therefore replicate the results of Experiment 1 regarding appropriate vs. inappropriate use of intonation and extend them to different locations within sentences and to passives as well as actives.

The absence of an effect of placing given information in the subject and new information in the object suggests that the syntactic marking of information structure may play a much smaller role in auditory sentence comprehension than intonational marking. This suggestion is strengthened by the absence of a difference between passives and actives in the effect of syntactic marking, because such marking is more explicit in passives (Anisfeld \& Klenbort, 1973; Hornby, 1974). Since previous experiments using the same paradigm, but with a reading rather than a listening task (Yekovich et al., 1979), have found that such syntactic cues produce faster comprehension times, these results point to an important difference between visual and auditory sentence comprehension.

The effect of voice, with passive sentences requiring more time to understand than actives, is consistent with the extensive literature on the problems of processing the more complex syntax of passives (e.g., Forster \& Olbrei, 1973; Gough, 1965). However, the interaction between appropriateness and voice indicates that these problems can be offset by appropriate intonational cuing of information structure. When such roles as agent and object are established in one sentence, and these roles or their perpetrators serve as antecedents for expressions in a subsequent sentence, clear marking of the relationships between the constituents of the two sentences may make it possible to determine the underlying conceptual structure of the second sentence without doing a full syntactic analysis. The interaction may thus be similar to that found for reversible vs. nonreversible actives and passives (Slobin, 1966).

The faster comprehension times for object-accented than for subject-accented unrelated sentences, and the trend toward such a difference for passive sentences, suggests that sentences with accent at the end may be generally easier to understand than sentences in which the accent is closer to the beginning. The increase in the duration of the final part of the sentence that would normally accompany object stress provides additional 
time to integrate the sentences and relate them to their contexts, activities that seem generally to be carried out at the ends of clauses or sentences (Aaronson \& Scarborough, 1976; Just \& Carpenter, 1978, 1980). This extra time might be expected to benefit primarily sentences for which comprehension is impeded by such factors as incoherent discourse relations (as for the unrelated sentences) or difficult syntactic structure (as for passives). Alternatively, the difference may simply reflect a bias toward object-accented sentences: Object accent may be somewhat more natural than accent elsewhere in sentences (Cutler \& Isard, 1980; however, see Bolinger, 1972, and Schmerling, 1974).

\section{GENERAL DISCUSSION}

The two experiments reported above demonstrate that the appropriate use of intonation to mark information structure facilitates the comprehension of sentences. In Experiment 1, accenting focal information produced faster comprehension times than accenting nonfocal information. In Experiment 2, comprehension times were faster when new information was accented and given information was not, compared to comprehension times for sentences in which given information was accented. This pattern of effects conforms to hypotheses derived from linguistic observations of the discourse correlates of variations in the intonation patterns of sentences (Chafe, 1974, 1976; Cutler \& Isard, 1980; Halliday, 1967): The information focus of a sentence, or the part that carries information new to the discourse, is also the part that is normally accented.

Experiment 1 suggested that the appropriate accenting of a sentence facilitates comprehension not only relative to inappropriate accenting, but also relative to sentences with a neutral intonation contour. This was true both for context sentences and for target sentences, for different but related reasons: The presence of accent in context sentences served to clearly mark a discourse presupposition necessary for the comprehension of subsequent targets, whereas appropriate intonation patterns in targets indicated the information focus. Comprehension times for target sentences were faster when contexts were appropriately accented than when they had no accent, and when the targets themselves were appropriately accented than when they were not. These findings, together with those for appropriate vs. inappropriate accenting of the information in target sentences, are consistent with previous experiments that have shown that both the availability of contextual antecedents and the marking of information structure are important to the processing of sentences in connected discourse (Carpenter \& Just, 1977a, 1977b; Garrod \& Sanford, 1977; Haviland \& Clark, 1974; Yekovich \& Walker, 1978; Yekovich et al., 1979).

A major problem in comparing effects for sentences containing accent with those that do not is that the perception of increased stress tends to be associated with an increase in the duration of a sentence (Lehiste, 1970), and this was true in Experiment 1. However, presence of accent did not significantly reduce comprehension times for the context sentences themselves, indicating that the combination of accent and greater duration does not reliably affect the time required to understand an isolated sentence. Obviously, however, further research will be required to determine the contribution of time to the effect of accent on comprehension.

Experiment 2 examined the effects of intonational vs. syntactic marking of information structure on comprehension time. Given information tends to occur toward the beginning of a sentence, and new information toward the end (Firbas, 1966), perhaps optimally, with given information in the subject and new information in the object (Halliday, 1970). Consistent with such a pattern, Yekovich et al. (1979) found that placing given information in the surface subject, and new information in the object, facilitated comprehension relative to the opposite arrangement. Experiment 2, however, found no significant effect of the location of given and new information within target sentences, for either active or passive sentences: Comprehension times for both positions depended primarily on whether their intonation was appropriate for the status (given or new) of the information they carried. It therefore appears that the position of given and new information may play a much less important role than their intonation in auditory sentence comprehension: Since spoken language has prosodic stress available as a means to mark information structure, listeners may rely less on positional cues. This is consistent with evidence that intonation is the primary indicator of information structure in English (MacWhinney \& Bates, 1978).

These results are particularly interesting in light of speculations about the effect on reading comprehension of the absence or relative paucity of explicit cues to intended intonation in visual language (Olson, 1977; Schallert, Kleiman, \& Rubin, Note 2). To compensate, location may perform a function in writing that it does not ordinarily serve in spoken language, or that it serves inadvertently as a byproduct of a bias toward placing the accent in sentences near the end (Cutler \& Isard, 1980). Bolinger (1957) and Schubiger (1964) have noted the possibility of using certain syntactic structures to maneuver new information to the ends of sentences; proficient writers apparently do this routinely (Smith, 1971). Beginning readers may need to learn to use position as a cue to information structure, as a partial replacement for the intonational cues provided in spoken language.

The interpretation of the present experiments rests in part on the assumption that contrastive information is processed similarly to new information, since the sentences employed were in many cases paradigmatic examples of contrastiveness. There is a recurrent debate among linguists concerning the nature of the distinction between newness and contrastiveness. According to criteria proposed by Chafe (1976), what separates contrastive from new information is that, in the case of 
contrastiveness, the speaker believes the hearer to have a very limited number of candidates in mind for a particular role. Thus, the word "artichokes" in a sentence such as "He ate some ARTICHOKES" would most probably be new following a statement such as "Herman ate something for dinner he's never had before," but contrastive following the statement "It wasn't anchovies that Herman ate." Moreover, Chafe maintains that contrastive accent differs in prominence from the accent that accompanies new information. Bolinger (1961, 1978), on the other hand, argues that the accent marking contrastiveness does not differ from that marking new information, and that the contrastive function is not qualitatively different from that of conveying new information.

It seems clear that the discourse presuppositions for sentences viewed as being contrastive are more stringent than those for sentences that simply carry new information; the issue appears to be whether this restrictiveness is only the end of a continuum or a unique status. The same is true for accent. The problem for the present experiments, given that the discourse presuppositions and intonation patterns used were contrastive, is whether the listener processes such information differently than new information.

In terms of the given-new strategy proposed by Clark and Haviland (1977), it is reasonable to assume that the processing of new and contrastive information is similar. The focus of a contrast in a sentence is clearly the most informative part; the remaining information tends to be given. The given information must have a unique antecedent in memory, consisting of the background information (Chafe, 1976) or presupposition established by the context. Finally, the contrastive information, like new information, must be integrated into memory for comprehension to be complete. Although additional steps may be required in the case of a contrast (e.g., as in a denial, it may be necessary for contrastive information to displace previously stored information as part of its integration into memory, cf. Clark \& Clark, 1977), the basic operations should be the same. The overall convergence between the current results and those of previous experiments on the processing of given and new information supports this claim.

In summary, the experiments reported here provide evidence for a substantial contribution of intonation to conveying information structure in auditory sentence comprehension. The appropriate use of accent to mark the new information in a sentence facilitates comprehension relative to conditions in which accent is absent or used inappropriately. As a cue to information structure in listening, intonation also appears to play a greater role than the syntactic device of surface position (subject vs. object). These effects point to the fundamental importance of intonation in conveying information structure in spoken English.

\section{REFERENCE NOTES}

1. Hornsby, M. E., Carr, T. H., \& Bock, J. K. Prosodic stress directs attention and can't be ignored in verifying descriptions. Paper presented at the meeting of the Western Psychological Association, San Francisco, April 1978.

2. Schallert, D. L., Kleiman, G. M., \& Rubin, A. D. Analyses of differences between written and oral language (Tech. Rep. 29). Urbana-Champaign, Ill: University of Illinois, Center for the Study of Reading, 1977.

\section{REFERENCES}

Aaronson, D., \& Scarborough, H. S. Performance theories for sentence coding: Some quantitative evidence. Journal of Experimental Psychology: Human Perception and Performance, 1976, 2, 56-70.

Anisfeld, M., \& Klenbort, I. On the functions of structural paraphrase: The view from the passive voice. Psychological Bulletin, 1973, 79, 117-126.

Bock, J. K. The effect of a pragmatic presupposition on syntactic structure in question answering. Journal of Verbal Learning and Verbal Behavior, 1977, 16, 723-734.

Bock, J. K., \& Inwin, D. E. Syntactic effects of information availability in sentence production. Journal of Verbal Learning and Verbal Behavior, 1980, 19, 467-484.

Bolinger, D. Maneuvering for accent and position. College Composition and Communication, 1957, 8, 234-238.

Bolinger, D. Contrastive accent and contrastive stress. Language, 1961, 37, 83-96.

Bolinger, D. Accent is predictable (if you're a mind-reader). Language, 1972, 48, 633-644.

Bolinoer, D. Intonation across languages. In J. H. Greenberg (Ed.), Universals of human language (Vol. 2): Phonology. Stanford: Stanford University Press, 1978.

Carpenter, P. A., \& Just, M. A. Integrative processes in comprehension. In D. LaBerge \& S. J. Samuels (Eds.), Basic processes in reading: Perception and comprehension. Hillsdale, N.J: Erlbaum, 1977. (a)

Carpenter, P. A., \& Just, M. A. Reading comprehension as eyes see it. In M. Just \& P. Carpenter (Eds.), Cognitive processes in comprehension. Hillsdale, N.J: Erlbaum, 1977. (b)

CHAFE, W. L. Meaning and the structure of language. Chicago: University of Chicago Press, 1970.

Chafe, W. L. Language and consciousness. Language, 1974, S0, 111-133.

Chafe, W. L. Givenness, contrastiveness, definiteness, subjects, topics, and point of view. In C. N. Li (Ed.), Subject and topic. New York: Academic Press, 1976.

Сномsкy, N. Deep structure, surface structure, and semantic interpretation. In D. D. Steinberg \& L. A. Jakobovits (Eds.), Semantics: An interdisciplinary reader in philosophy, linguistics and psychology. Cambridge: Cambridge University Press, 1971.

Clark, H. H. The language-as-fixed-effect fallacy: A critique of language statistics in psychological research. Journal of Verbal Learning and Verbal Behavior, 1973, 12, 335-359.

Clark, H. H., \& Clank, E. V. Psychology and language. New York: Harcourt Brace Jovanovich, 1977.

Clark, H. H., \& Haviland, S. E. Comprehension and the givennew contract. In R. O. Freedle (Ed.), Discourse production and comprehension (Vol. 1). Norwood, N.J: Ablex, 1977.

Clark, H. H., \& Sengul, C. J. In search of referents for nouns and pronouns. Memory \& Cognition, 1979, 7, 35-41.

Coleman, E. B. Generalization effects vs. random effects: Is oth a source of Type 1 or Type 2 error? Journal of Verbal Learning and Verbal Behavior, 1979, 18, 243-256.

Cutlen, A. Beyond parsing and lexical look-up: An enriched description of auditory sentence comprehension. In R. J. Wales \& E. C. T. Walker (Eds.), New approaches to language mechanisms. Amsterdam: North-Holland, 1976.

Cutler, A., \& Fodor, J. A. Semantic focus and sentence comprehension. Cognition, 1979, 7, 49-59.

CUTLER, A., \& ISARD, S. D. The production of prosody. In B. Butterworth (Ed.), Language production (Vol. 1). London: Academic Press, 1980. 
Dooling, D. J. Rhythm and syntax in sentence perception. Journal of Verbal Learning and Verbal Behavior, 1974, 13, 255-264.

Firbas, J. On defining the theme in functional sentence analysis. Travaux Linguistiques de Prague, 1966, 1, 267-280.

Forster, K. I., \& OlbreI, I. Semantic heuristics and syntactic analysis. Cognition, 1973, 2, 319-347.

GARROD, S., \& SANFord, A. Interpreting anaphoric relations: The integration of semantic information while reading. Journal of Verbal Learning and Verbal Behavior, 1977, 16, 77-90.

GEERs, A. E. Intonation contour and syntactic structure as predictors of apparent segmentation. Journal of Experimental Psychology: Human Perception and Performance, 1978, 4, 273-283.

Govar, P. B. Grammatical transformations and speed of understanding. Journal of Verbal Learning and Verbal Behavior, $1965,4,107-111$.

Gunter, $\mathrm{R}$. On the placement of accent in dialogue: $A$ feature of context grammar. Journal of Linguistics, 1966, 2, 159-179.

HALliday, M. A. K. Notes on transitivity and theme in English. Part 2. Journal of Linguistics, 1967, 3, 199-244.

Halliday, M. A. K. Language structure and language function. In J. Lyons (Ed.), New horizons in linguistics. Baltimore: Penguin, 1970.

Haviland, S. E., \& Clark, H. H. What's new? Acquiring new information as a process in comprehension. Journal of Verbal Learning and Verbal Behavior, 1974, 13, 512-521.

Honnby, P. A. Surface structure and the topic-comment distinction: A developmental study. Child Development, 1971, 42, 1975-1988.

Hornsy, P. A. The psychological subject and predicate. Cognitive Psychology, 1972, 3, 632-642.

Honnby, P. A. Surface structure and presupposition. Journal of Verbal Learning and Verbal Behavior, 1974, 13, 530-538.

Hoxnsy, P. A., HAss, W. A. Use of contrastive stress by preachool children. Journal of Speech and Hearing Research, 1970, 13, 395-399.

Just, M. A., \& CARpenter, P. A. Inference processes during reading: Reflections from eye fixations. In J. W. Senders, D. F. Fisher, \& R. A. Monty (Eds.), Eye movements and the higher psychological functions. Hillsdale, N.J: Erlbaum, 1978.

Just, M. A., \& Carpenter, P. A. A theory of reading: From eye fixations to comprehension. Psychological Review, 1980 , 87, 329-354.

LANafond, J., \& Holmes, V. M. Syntactic presupposition in sentence comprehension. Cognition, 1979, 7, 363-383.
Lenists, I. Suprasegmentals. Cambridge, Mass: MIT Press, 1970.

MacWhinney, B., \& Bates, E. Sentential devices for conveying givenness and newness: A cross-cultural developmental study. Journal of Verbal Learning and Verbal Behavior, 1978, 17, 539-558.

O'Connell, D. C., Turner, E. A., \& OnusKa, L. A. Intonation, grammatical structure, and contextual association in immediate recall. Journal of Verbal Learning and Verbal Behavior, 1968, 7, 110-116.

Ouson, D. From utterances to text: The bias of language in speech and writing. Harvard Educational Review, 1977, 47, 257-281.

Schmerhing, S. F. A re-examination of normal stress. Language, 1974, 50, 66-73.

Schubigen, M. The interplay and cooperation of word order and intonation in English. In D. Abercrombie, D. B. Fry, P. A. D. MacCarthy, N. C. Scott, \& J. L. M. Trim (Eds.), In honour of Daniel Jones: Papers contributed on the occasion of his eightieth birthday. London: Longmans, Green, 1964.

Shields, J. L., McHugr, A., \& Martin, J. G. Reaction time to phoneme targets as a function of rhythmic cues in continuous speech. Journal of Experimental Psychology, 1974, 102, 250-255.

SLOBIN, D. I. Grammatical transformations and sentence comprehension in childhood and adulthood. Journal of Verbal Learning and Verbal Behavior, 1966, 5, 219-227.

Sмгтн, C. Sentences in discourse. Journal of Linguistics, 1971, 7, 213-235.

VAN Disk, T. A. Text and context: Explorations in the semantics and pragmatics of discourse. London: Longman, 1977.

WEENER, P. Language structure and the free recall of verbal messages by children. Developmental Psychology, 1971, 5, 237-243.

Wieman, L. A. Stress patterns of early child language. Journal of Child Language, 1976, 3, 283-286.

Wingrield, A., \& KLEIN, J. F. Syntactic structure and acoustic pattern in speech perception. Perception \& Psychophysics, 1971, 9, 23-25.

Yerovich, F. R., \& Walker, C. H. Identifying and using referents in sentence comprehension. Journal of Verbal Learning and Verbal Behavior, 1978, 17, 265-277.

Yerovich, F. R., Walem, C. H., \& Blaceman, H. S. The role of presupposed and focal information in integrating sentences. Journal of Verbal Learning and Verbal Behavior, 1979, 18, 535-548.

Appendix A

Experiment 1 Sentence Pairs

George $_{\mathrm{A}}$ didn't kill Bill I. $_{\text {Alfred killed Bill. }}$.

Lynn A didn't go to Brazil 1 . Joan went to Brazil.

Arnold ${ }_{\mathrm{A}}$ didn't fix $\mathrm{I}$ the radio. Doris fixed the radio.

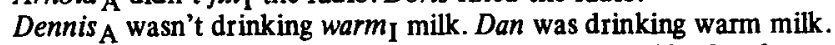

Henry doesn't have an older sister $_{\mathrm{A}}$. Henry has an older brother.

Frank isn't growing I beard $\mathrm{A}$. Frank is growing a moustache.

Ray didn't play football in college $_{\mathrm{I}}$. Ray played baseball in college.

Jack $_{\mathrm{I}}$ isn't reading a newspaper ${ }_{\mathrm{A}}$. Jack is reading a magazine.

Jill $_{\mathrm{I}}$ doesn't take dancing $\mathrm{A}$ lessons. Jill takes singing lessons.

Marcia isn't wearing ${ }_{I}$ a red ${ }_{\mathrm{A}}$ coat. Marcia is wearing a blue coat.

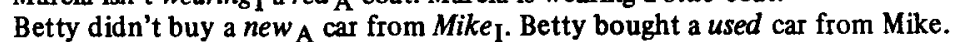

The plastic ${ }_{\mathrm{A}}$ bottle $\mathrm{I}_{\mathrm{I}}$ didn't break. The glass bottle broke.

Harry doesn't live I near Chicago A. Harry lives near Detroit.

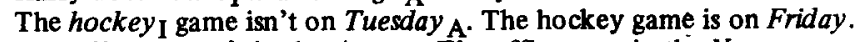

The officer I wasn't in the Army A. The officer was in the Navy.

John didn't get a job $b_{1}$ in Michigan A. John got a job in Wisconsin.

Marvin $_{\mathrm{I}}$ doesn't own $\mathrm{A}_{\mathrm{A}}$ the building. Marvin rents the building.

Alice didn't buy A $_{\text {and }}$ the bana ${ }_{\text {I }}$ bread. Alice baked the banana bread.

Ralph didn't direct ${ }_{\mathrm{A}}$ the movie $\mathrm{I}_{\mathrm{I}}$. Ralph produced the movie.

Jane didn't get married A $_{\mathrm{A}}$ in I $_{\mathrm{I}}$. Jane got divorced in June.

Note-Italic type indicates possible accent positions. In context sentences, subscripted $A$ and I mark accent locations in the appropriate and inappropriate conditions, respectively. 
Appendix B

Experiment 2 Context and Target Sentences

\begin{tabular}{|c|c|c|}
\hline & Contexts & Targets \\
\hline 10 & Evelyn kissed Jeremy. & Rhonda kissed Jeremy too. \\
\hline is & Rhonda kissed Jason. & 1P Jeremy was kissed by Rhonda too. \\
\hline $1 \mathrm{U}$ & Lila kissed Michael. & \\
\hline 20 & Carolyn planted daffodils. & 2A Jennifer planted daffodils too. \\
\hline $2 S$ & Jennifer planted marigolds. & 2P Daffodils were planted by Jennifer too. \\
\hline $2 \mathrm{U}$ & Josephine planted tulips. & \\
\hline 30 & Vanessa fed the ducks. & 3A Margaret fed the ducks too. \\
\hline $3 \mathrm{~S}$ & Margaret fed the pigeons. & 3P The ducks were fed by Margaret too. \\
\hline $3 \mathbf{U}$ & Colleen fed the sparrows. & \\
\hline 40 & Jack paid the carpenter. & 4A Mary paid the carpenter too. \\
\hline $4 S$ & Mary paid the electrician. & The carpenter was paid by Mary too. \\
\hline $4 U$ & Denise paid the housekeeper. & \\
\hline 50 & Jane slapped Edgar. & Vivian slapped Edgar too. \\
\hline $5 S$ & Vivian slapped Carlos. & Edgar was slapped by Vivian too. \\
\hline $5 U$ & Jill slapped Irving. & \\
\hline 60 & The jeweler sells watches. & The peddler sells watches too. \\
\hline $6 S$ & & 6P Watches are sold by the peddler too. \\
\hline 70 & $\begin{array}{l}\text { The grocer sells apples. } \\
\text { Brenda hit the Cadillac. }\end{array}$ & 7A Mildred hit the Cadillac too. \\
\hline $7 S$ & Mildred hit the stop sign. & 7P The Cadillac was hit by Mildred too. \\
\hline $7 \mathbf{U}$ & Geraldine hit the lamppost. & \\
\hline 80 & Marilyn shot the burglar. & 8A Harvey shot the burglar too. \\
\hline $8 \mathrm{~S}$ & Harvey shot the policeman. & 8P The burglar was shot by Harvey too. \\
\hline $8 \mathrm{U}$ & Darlene shot the fireman. & \\
\hline 90 & Gertrude saw the airplane. & 9A Patrick saw the airplane too. \\
\hline 9S & Patrick saw the helicopter. & 9P The airplane was seen by Patrick too. \\
\hline $9 \mathbf{U}$ & Helen saw the sailboat. & \\
\hline 100 & George petted the dog. & 10A Harry petted the dog too. \\
\hline $10 \mathrm{~S}$ & Harry petted the cat. & 10P The dog was petted by Harry too. \\
\hline $10 \mathrm{U}$ & Sylvia petted the monkey. & \\
\hline 110 & Jim kicked the trashcan. & $11 \mathrm{~A} \mathrm{Bob}$ kicked the trashcan too. \\
\hline $11 \mathrm{~S}$ & Bob kicked the footstool. & $11 \mathrm{P}$ The trashcan was kicked by $B o b$ too. \\
\hline $11 \mathrm{U}$ & Brian kicked the television. & \\
\hline 120 & Emily wrecked the truck. & 12A Ronald wrecked the truck too. \\
\hline $12 S$ & Ronald wrecked the car. & 12P The truck was wrecked by Ronald too. \\
\hline $12 \mathrm{U}$ & Linda wrecked the bicycle. & \\
\hline 130 & Laura didn't bake the cookies. & 13A Hannah didn't bake the cookies either. \\
\hline $13 S$ & Hannah didn't bake the cake. & 13P The cookies weren't baked by Hannah either. \\
\hline $13 \mathrm{U}$ & Roxanne didn't bake the bread. & \\
\hline 140 & Barney didn't train the lion. & 14A Frank didn't train the lion either. \\
\hline $14 S$ & Frank didn't train the tiger. & 14P The lion wasn't trained by Frank either. \\
\hline $14 U$ & Dave didn't train the walrus. & \\
\hline 150 & Maxine didn't write the novel. & 15 A Deborah didn't write the novel either. \\
\hline $15 \mathrm{~S}$ & Deborah didn't write the poem. & 15P The novel wasn't written by Deborah either. \\
\hline $15 \mathrm{U}$ & Patricia didn't write the article. & \\
\hline 160 & Sylvester didn't build the house. & 16A Reginald didn't build the house either. \\
\hline $16 S$ & $\begin{array}{l}\text { Reginald didn't build the garage. } \\
\text { Albert didn't build the tool shed. }\end{array}$ & 16P The house wasn't built by Reginald either. \\
\hline $\begin{array}{l}160 \\
170\end{array}$ & & 17A Jerry didn't paint the mailbox either. \\
\hline $17 \mathrm{~S}$ & Jerry didn't paint the bench. & 17P The mailbox wasn't painted by Jerry either. \\
\hline $17 \mathrm{U}$ & Charlie didn't paint the fence. & \\
\hline 180 & Jessica didn't recommend Walter. & 18A Janet didn't recommend Walter either. \\
\hline $18 \mathrm{~S}$ & Janet didn't recommend Elizabeth. & $18 \mathrm{P}$ Walter wasn't recommended by Janet either. \\
\hline $18 \mathrm{U}$ & Alice didn't recommend Melvin. & \\
\hline 190 & Louise didn't kill Daniel. & 19A Phyllis didn't kill Daniel either. \\
\hline $19 \mathrm{~S}$ & Phyllis didn't kill Howard. & 19P Daniel wasn't killed by Phyllis either. \\
\hline $19 \mathrm{U}$ & Susan didn’t kill Herbert. & \\
\hline 200 & Mabel didn't steal the canary. & 20A Agnes didn't steal the canary either. \\
\hline $20 \mathrm{~S}$ & Agnes didn't steal the parakeet. & 20P The canary wasn't stolen by Agnes either. \\
\hline $20 U$ & Oliver didn't steal the penguin. & \\
\hline 210 & Virgil didn't compliment Andrea. & 21 A Roscoe didn't compliment $A$ Andrea either. \\
\hline $\begin{array}{l}21 \mathrm{~S} \\
21 \mathrm{U}\end{array}$ & $\begin{array}{l}\text { Roscoe didn't compliment Gloria. } \\
\text { Anthony didn't compliment Gina. }\end{array}$ & $21 \mathrm{P}$ Andrea wasn't complimented by Roscoe either. \\
\hline 220 & Fred didn't play the trumpet. & 22A Carl didn't play the trumpet either. \\
\hline $\begin{array}{l}22 \mathrm{~S} \\
22 \mathrm{U}\end{array}$ & $\begin{array}{l}\text { Carl didn't play the clarinet. } \\
\text { Mathew didn't play the tuba }\end{array}$ & 22P The trumpet wasn't played by Carl either. \\
\hline
\end{tabular}


230 Molly didn't help Bill.

23A Joan didn't help Bill either.

23S Joan didn't help Bruce.

23P Bill wasn't helped by Joan either.

23U Karen didn't help Mark.

240 The principal didn't fix the projector.

24A The teacher didn't fix the projector either.

24S The teacher didn't fix the camera.

24U The coach didn't fix the net.

$24 \mathrm{P}$ The projector wasn't fixed by the teacher either.

Note-Contexts: $O=$ matches active object and passive subject; $S=$ matches active subject and passive object; $U=$ unrelated. Targets: $A=$ active; $P=$ passive. Italic type indicates possible accent position. In subject-accented conditions, the head noun of the subject noun phrase was accented. In object-accented conditions, the head noun of the object noun phrase was accented.

(Received for publication November 24, 1981;

revision accepted July 22,1982 .) 